\title{
Hydrothermal alteration as source for vein quartz in a fossil geothermal system in SW Iceland
}

\author{
ALINA YAPPAROVA ${ }^{1}$, DMITRII A. KULIK ${ }^{2}$, GEORGE \\ DAN MIRON $^{3}$ AND THOMAS DRIESNER $^{4}$ \\ ${ }^{1}$ ETH Zurich \\ ${ }^{2}$ Paul Scherrer Institut \\ ${ }^{3}$ Paul Scherrer Institute \\ ${ }^{4}$ Swiss Federal Institute of Technology Zürich \\ Presenting Author: alina.yapparova@erdw.ethz.ch
}

This study quantifies mass transfer during reactive flow in a fossil geothermal system, preserved in fractured basaltic lava flow formation at Hvallfjordur in SW Iceland. Samples of unaltered host rock, a quartz-filled fracture zone and the surrounding alteration halo were analyzed by XRF, XRD and SEM. Modal compositions of the three rock types were calculated from the analyses, and the temperature $\left(250^{\circ} \mathrm{C}\right)$ of the hydrothermal alteration has been estimated from fluid inclusions microthermometry and the alteration mineral assemblage [1].

We have attempted to reconstruct the alteration process of the basaltic host rock by the inflowing geothermal fluid by means of reactive transport modelling using CSMP++GEM code [2] equipped with the MINES thermodynamic database [3]. Our 2D model is a $1 \mathrm{~m} \times 0.5 \mathrm{~m}$ rectangle, cross-cut by a thin $3 \mathrm{~cm}$ fracture of a higher permeability. The fluid enters the model at the bottom of the fracture region and both the advective ( $2 \mathrm{~m} / \mathrm{yr})$ and diffusive $(\sim 3 \mathrm{~cm} / \mathrm{yr})$ fluxes are taken into account.

The modeled unaltered basaltic rock consists of pure endmembers of clinopyroxene, olivine and plagioclase solid solutions, chlorites, and ilmenite. Input water composition at $250^{\circ} \mathrm{C}(\mathrm{pH}=6)$ was based on the data from [4], who measured low salinity geothermal water samples from high temperature wells.

Geothermal water flowing up the fracture diffuses slowly into the adjacent host rock. Olivine, pyroxene and plagioclase react to chlorites, calcite and quartz in the growing alteration halo and the fracture itself becomes gradually filled with quartz and pyrite. Our simulation results reproduce the mineral assemblage observed in the field samples and mass balance shows that the silica needed for the extensive quartz veining can entirely be sourced from the alteration in the host rock.

[1] Thien, B. et al. (2016), Unpublished internal report, ETH Zürich, 2016.

[2] Yapparova, A. et al. (2017), Transport in Porous Media, 117(3), 385-413.

[3] Gysi, A.P. (2017), Pure and Applied Chemistry 89, 581596.

[4] Kaasalainen, H. et al. (2015), Applied Geochemistry, 62, 207-223. 